\title{
Experiences of Midwives for Caring Unbooked Pregnant Mothers in a Maternity Unit at a District Hospital in the Eastern Cape Province
}

\author{
Sithembele Magqadiyane \\ Life St Mary Private Hospital, Mthatha, South Africa \\ Email: smagqadiyane@gmail.com
}

How to cite this paper: Magqadiyane, S. (2020) Experiences of Midwives for Caring Unbooked Pregnant Mothers in a Maternity Unit at a District Hospital in the Eastern Cape Province. Advances in Reproductive Sciences, 8, 186-200.

https://doi.org/10.4236/arsci.2020.84016

Received: April 16, 2020

Accepted: October 9, 2020

Published: October 12, 2020

Copyright ( 2020 by author(s) and Scientific Research Publishing Inc. This work is licensed under the Creative Commons Attribution International License (CC BY 4.0).

http://creativecommons.org/licenses/by/4.0/

\begin{abstract}
Background: South Africa struggles to improve maternal health outcomes resulting to its failure to achieve millennium development goal for maternal health. Non-utilisation of antenatal health services by pregnant mothers is the leading cause of unbooked cases that complicate the labour stages. Purpose: The purpose of the study was to explore the experiences of midwives for caring unbooked pregnant women in a maternity unit at a district hospital in the Eastern Cape province of South Africa. Design and Methods: A phenomenological approach was adopted in this study. Specifically, a descriptive phenomenological deign was used to explore midwives' experiences for caring unbooked pregnant women in maternity ward of a district hospital on six (6) purposively selected midwives. In this study, the researcher utilised individual, semi structured phenomenological interviews to collect data from midwives caring for unbooked pregnant mothers in a maternity unit. Data saturation was reached after carrying out the six interviews. These interviews were audio taped and transcribed verbatim and Interpretative Phenomenological Analysis framework steps method of qualitative data was applied to analyse the collected data. Results: Three thematic categories emerged from data analysis: 1) Experiences of midwives, which interfered with emotional challenges leading to fear and anxiety. Experiences of midwives were also associated with shortage of midwives and leading to maternal incidences. 2) Caring for unbooked pregnant mothers interfered with incompetency and inexperienced midwives and reported a lack of debriefing. 3) Support system which was seen as lacking from managers. Conclusion: The study recommended collaboration with primary health care clinics including community leaders, and employment of highly skilled professionals and in-service trainings of the current midwives to minimise unnecessary incidences.
\end{abstract}




\section{Keywords}

Caring, Experiences, Maternity Unit, Midwives, Unbooked Pregnant Mothers

\section{Introduction and Background Information}

South Africa is struggling to improve maternal and perinatal outcomes as there is a failure to attain millennium development goal for maternal health [1]. Most of the factors leading to this failure include negative attitudes of nurses towards pregnant women and lack of skills on handling pregnant women. Therefore, these are leading causes of poor health outcomes in the maternal health. South Africa is among few countries in the world with a very poor performance on maternal and child health outcomes [2]. This is a national concern and multiple urgent, concerted and effective interventions at various levels of governance were put in place. The aim was to improve Maternal, New-born and Child Health $(\mathrm{MNCH})$ outcomes [3]. The existence of the afore-mentioned maternal health factors including poor perinatal outcomes was highly associated with non-utilisation of antenatal and delivery care services.

However, these is a revelation that women with poor socioeconomic difficulties are more likely to attend antenatal care services and they end up being "unbooked patients" during labour stages [4].

Further, women with good socioeconomic conditions are likely to attend their antenatal care services as a result $90 \%$ of them booked their labour stages. Therefore, improving socioeconomic status of women could minimise unnecessary maternal losses. Though South Africa has implemented primary healthcare re-engineering program to deliver services in the communities, it is still struggling to trace pregnant mothers for antenatal care services [5]. This problem continues leading to many women reporting as unbooked patients in hospital settings. However, having intervention on issues related to unbooked cases would help saving the lives of both pregnant women and their infants.

A study in Nigeria on unbooked patients' impact found that these types of patients have missed potential benefits of antenatal care services and contribute into high maternal and perinatal mortality [5]. These are the women who, for one reason or other failed to seek antenatal care services in a modern facility.

Comparative studies of booked and unbooked patients demonstrate that the unbooked patient is a woman with limited resources and that pregnancy outcome from unbooked clients is often high risk [6]. Many types of these patients usually present with a prolonged and complicated labour. Their babies are likely to be smaller than their booked counterparts and over $60 \%$ of them had various complications of pregnancy, labour and delivery.

In addition, the unbooked pregnant mothers are regarded as a public concern in the African countries [5]. This was based on a number of plenty articles that have shown the ineffectiveness of antenatal care services. A retrospective study 
conducted in Nigeria on experiences of unbooked pregnant mothers reported that a total of $5962(80.7 \%)$ pregnant women presented in labour ward; 616 (10.3\%) of them were reported as unbooked cases [7]. This study reported many labour complications including neonatal and maternal deaths.

In United Kingdom, a study on understanding the delayed access to antenatal care found that there was an increase in infant, foetal and maternal mortality emanating from poor attendance of antenatal health care services by pregnant women [8]. The study also found that these pregnant mothers have inadequacy knowledge on reproductive health services. This contributes to the delays in their early pregnant diagnosis [8].

A study conducted in sub-Saharan Africa on reasons of women not using antenatal care service found that the high maternal mortalities are associated with unbooked pregnant mothers [9]. These circumstances affect middle and Low Countries to achieve millennium development goal for improving maternal health. In Kwazulu natal Province of South Africa, a study on non-utilisation of antenatal healthcare services found that, $(n=60,000)$ deliveries conducted, $56 \%$ $(n=33,600)$ of them were unbooked pregnant mothers while $44 \%(n=26,400)$ were booked cases [10]. The majority of these unbooked cases contributed to multiple incidences reported like maternal and neonatal deaths. Further, where there are cases of unbooked pregnant cases there is likelihood that many low birth weight infants, high perinatal mortality and Born-Before-Arrival as compared to booked ones.

However, Midwives are the frontline essential practitioners and the continuation of these unbearable circumstances could lead to emotional stress of midwives because in their profession unsuccessful deliveries are unacceptable and it is regarded as a crucial matter in their profession [11]. Therefore, to minimise these complications from happening, the study would explore their experiences on caring these types of patients and establish recommendation thereafter.

\section{Statement of the Research Problem}

Universally, countries including South Africa adopted millennium development goals (MDGs) to strengthen their health systems [12]. However, South Africa continually struggles to attain MDG5 as a result it fails to improve maternal health [1]. The fact is that multiparous contribute to this poor maternal health. Many studies found that multiparous women who had previous successful deliveries independently felt overconfident and refused to seek antenatal care and delivery in modern facilities [13]. As a result, there are $70 \%$ of unbooked pregnant cases reported as compared to their counterpart cases in South Africa. Consequently, late labour presentations inevitable interventions are associated with unbooked pregnant mothers. These mothers are those who went straight to maternity ward without the approval of any primary health care facility, sometimes they are referred to as "self-referrals". Most of these deliveries went unsuccessful. The study explored the experiences of midwives for caring unbooked 
pregnant mothers in a maternity unit in order to develop strategies that enhance high uptake of utilization of antenatal healthcare services and improve quality of maternal health services in a hospital setting.

\section{Research Question}

The following research question was formulated: What are the experiences of registered midwives caring unbooked pregnant mothers? This was translated for the participants as: "Explain in your views, how do you experience caring and managing unbooked pregnant mothers in maternity ward?" Subsequent questions arose from the participants' descriptions of their experience.

\section{Purpose and Objective of the Study}

The purpose of the study was to explore midwives' experiences for caring unbooked pregnant mothers in maternity ward of district hospital in the Eastern Cape of South Africa. To achieve this purpose, the researcher sought to determine and explore the lived experiences of midwives caring unbooked pregnant mothers.

\section{Significance of the Study}

The findings of the study will facilitate the formulation of guidelines for proper management of unbooked pregnant women. Equipping registered midwives with counselling, coping skills and competencies will strengthen and advance their nursing skills working with pregnant women. The study could enlighten nurse managers and policy-makers on the experiences of midwives providing management of unbooked pregnant women. Results of the study could enable primary healthcare services to improve the quality of antenatal care services.

\section{Definitions of Key Words}

Caring in this study refers to the compassion, usefulness, moral support and care that the midwives show about unbooked pregnant mothers who came for labour.

Experiences in this study refer to the circumstances or events experienced by midwives while caring for unbooked pregnant mothers.

Maternity unit in this study refers to an accredited health facility unit that specialising in caring for pregnant mothers during labour and delivery procedures.

Midwives in this study refers to a nurse who has registered with the South African Nursing Council as a midwife and is in possession of the appropriate qualification(s) in Basic or Advanced Midwifery Nursing Science, and who cares for pregnant mothers in a public hospital in the Eastern Cape Province.

Unbooked pregnant mothers in this study refers to mothers who have not received adequate antenatal screening in a modern health facility and have just come straight into the health facility for labour and delivery purposes. 


\section{Research Design and Methodology}

A descriptive phenomenological qualitative study was chosen to describe human experiences of midwives caring unbooked pregnant mothers. The researcher adopted a phenomenological approach to explore the experiences of midwives through their descriptions of caring and managing unbooked pregnant mothers. These experiences are called "lived experiences". In addition, qualitative research involves the systematic collection and analysis of subjective data provided by involved people about the phenomena, including how they interpret the experiences and meaning attached to the experience.

\subsection{Population and Sample}

The population comprised selected registered midwives employed at the research site. The researcher used non-probability purposive sampling technique. This technique allows researcher to choose participants according to their knowledge and work experience on the subject phenomenon. For the eligibility of the study, the researcher chose only registered midwives or advanced midwives with more than one year in maternity unit. The size of the sample was considered satisfactory when data saturation was reached, implying that no new information was forthcoming during subsequent interviews. Data saturation was reached in $6^{\text {th }}$ participant and the researcher stopped interviews immediately.

\subsection{Ethical Principles}

The researcher considered the rights of the participants. The interviewer established trust between himself and the participants respected them as autonomous beings, thus enabling them to make sound decisions. The following ethical principles were also employed:

- Signing of informed consent by participants;

- Ensuring confidentiality throughout the study process;

- Ensure anonymity and protection from harm;

- Participants were fully informed and knew that they could withdraw from the study at any stage without incurring negative consequences;

- Participants were informed that if emotional issues arise, participants would be referred to a professional counsellor;

- Audio-taped interviews would be destroyed once transcribed;

- Transcriptions were kept in a locked cupboard at the researcher's home.

\subsection{Data Collection}

Data were gathered by means of semi structured phenomenological interviews. The interviews focused on the lived experiences of each participant with regard to caring of unbooked pregnant mother in maternity ward. The interviews gave the participants an opportunity to talk freely about their experience of caring unbooked pregnant women thereby giving the researcher an insight into their experience. As the interviews were semi structured, the participants and not the 
researcher controlled them. The researcher did not prepare a questionnaire as the questions arose from the participants' descriptions of their experience.

"Explain in your views, how do you experience caring and managing unbooked pregnant woman in maternity ward?" Subsequent questions arose from the participants' descriptions of their experience.

The interviewer created a context for the participants to speak freely and openly by utilising communication techniques such as clarification, paraphrasing, summarising, probing, and minimal verbal and non-verbal responses. The process was applied by the researcher to prevent the participants from feeling that they were being "cross-examined" on the topic. Participants' permission was obtained to audio-tape interviews. Comprehensive and accurate description was achieved by adding handwritten notes to the verbatim transcribed accounts. During the interviews, the interviewer used bracketing (placing preconceived ideas aside) and intuiting (focusing on the lived experience of the participants regarding the caring of unbooked pregnant women). The researcher continued interviewing participants until data saturation was reached as demonstrated by repeated themes.

\subsection{Data Analysis}

The researcher utilised a qualitative data analysis with rigour and care. Rigour in qualitative research refers to striving for excellence and is associated with discipline, scrupulous adherence and strict accuracy. All audio-recorded interviews were transcribed and transcripts were analysed manually using Interpretative Phenomenological Approach framework of analysis [14]. These stages of the analytical process are illustrated below:

Transcripts were analysed one at a time through the stages stated in Table 1. The analysis was conducted in parallel with the interviews until category saturation was achieved. The outcomes of the analysis are three categories, four themes, and four subthemes listed in Table 2. These thematic categories were discussed with excerpts from participants and supported by relevant literature review information.

\section{Measures to ensure trustworthiness}

Scientific rigor in qualitative studies, according to Grove, Gray \& Burns [15] is

Table 1. Stages of analysis.

\begin{tabular}{ll}
\hline Stage 1 & Reading and reading transcript to familiarize with participant's account \\
Stage 2 & Making notes of interesting issues \\
Stage 3 & $\begin{array}{l}\text { Development of emergent themes that capture meaning of participant's } \\
\text { Stage } 4\end{array}$ \\
Stage 5 & $\begin{array}{l}\text { Dearching for connections across emergent themes } \\
\text { and quotes from participants. }\end{array}$ \\
Stage 6 & $\begin{array}{l}\text { Development of a single master table of themes from master table of themes of } \\
\text { individual transcripts. }\end{array}$
\end{tabular}


Table 2. Characteristics of midwives.

\begin{tabular}{ccccccc}
\hline Identifier & $\begin{array}{c}\text { Age } \\
\text { group }\end{array}$ & Gender & $\begin{array}{c}\text { Race/population } \\
\text { group }\end{array}$ & Nursing category & $\begin{array}{c}\text { Years of } \\
\text { experience } \\
\text { as a nurse } \\
\text { (range) }\end{array}$ & $\begin{array}{c}\text { Years of } \\
\text { experience in } \\
\text { the maternity } \\
\text { unit (range) }\end{array}$ \\
\hline P1 & $35-39$ & Female & Black/African & Midwife (specialty) & $5-9$ & $5-9$ \\
P2 & $25-29$ & Female & Black/African & Midwife (General) & $10-14$ & $0-4$ \\
P3 & $35-39$ & Male & Black/Africa & Midwife (General) & $0-4$ & $0-4$ \\
P4 & $45-49$ & Female & Black/African & Midwife (specialty) & $0-4$ & $5-9$ \\
P5 & $45-49$ & Male & Black/African & $\begin{array}{c}\text { Midwife } \\
\text { (General) }\end{array}$ & $0-4$ & $0-4$ \\
P6 & $50-59$ & Female & Black/African & Midwife (General) & $5-9$ & $5-9$ \\
\hline
\end{tabular}

described as the degree to which the identified meaning represents the perspectives of the participants precisely. Trustworthiness refers to validity and reliability or objectivity in research. Measures to ensure trustworthiness of the study evaluate whether the findings reflect the participants' experience and not the researcher's perceptions. The four criteria for establishing trustworthiness, namely: credibility, dependability, conformability and transferability were applied in the study. However, Activities in achieving credibility were prolonged engagement in the field, keeping reflexive journals, the researcher's authority, peer reviews and structural coherence. Transferability was achieved through dense description of the data and purposive sampling. Dependability was achieved by a description of the method of data gathering, data analysis and interpretation. Confirmability was achieved by ensuring auditing of the entire research process and reflexive analysis.

\section{Socio Demographic Profile of Participants}

This section presents the characteristics of the participants based on their age, ethnic groups, race, their nursing categories, years of experiences as both nurse general and in a maternity unit as displayed in Table 3 underneath.

\section{Discussion of Research Results}

Discussion was based on schematic condensation of data in the table, and highlighted by direct quotations from the participants and relevant literature.

\section{- Experiences of midwives}

Although, the lives of both pregnant women and unborn baby depend on highly skilled midwives and medical doctors. These professionals especially, the midwives experience multiple challenges like poor working conditions, lack of basic equipment and shortage of highly skilled professionals to manage pregnant mothers.

It has been observed that department of health struggles to fill all required vacancies as suggested in the health establishment [16]. The continuity of this 
Table 3. Summary of themes that emerged during the study.

\begin{tabular}{lll}
\hline Themes & Categories & Subthemes \\
\hline - Experiences of midwives & - Emotional challenges & ○ Fear \\
& - Shortage and incompetence of midwives & $\circ$ Anxiety \\
& $\circ$ Maternal incidences \\
- Caring for unbooked & - Inexperienced midwives & $\circ$ Lack of debriefing. \\
pregnant women & & \\
- Support system & - Lack of support from managers & \\
\hline
\end{tabular}

situation compromises the expected quality of care provision especially in the maternal health facilities resulting in many incidences from shortage and litigations [16]. Therefore, employing highly skilled professionals such as advanced midwives and adequate medical doctors as the staff establishment suggested for each health facility would save millions of rand drained through litigations [17]. The researcher believed that employing these highly skilled midwives and medical doctors would improve the standards of care and minimise litigation cases against the department of health.

However, experiences of midwives are a main theme with two categories and two subthemes as determined in Table 3. These thematic categories will be discussed separately.

\section{- Emotional challenges}

According to care search last updated (i.e. 14 ${ }^{\text {th }}$ February 2017), it is normal to have changing feelings and emotions especially when there is a serious event or incidence that cause reaction. It was further stated that a person changes feelings because of existing external stimuli at the time [18]. In this study, the emotional challenges shed by the participants were based on the unique ideas, attitudes and beliefs formed by the experiences.

\section{○ Anxiety}

The majority of participants reported that they were anxious. Their anxiety was related to the fact that most of them are new in the unit and have no experience in maternity unit. One participant expressed her feeling as follow:

"It is so scary to manage a Head On Perineum (HOP) as new midwives... and I felt uncomfortable having to deliver a baby sometimes no chance to wear protective gloves in an unknown HIV status woman". PN1

Consistently, the abovementioned situation was similar with a study by Roets, Poggenpoel \& Myburgh [19] found that anxiety is a way of perceiving an uncertain and unpredictability situation and is aggravated by extrinsic factors like facing a new or different situation with inadequate knowledge on how to act on it. In this study, anxiety was caused by lacking of competence skills to manage and conduct deliveries during emergency period.

$\circ$ Fear

The majority of participants reported the complexity situation that they found themselves in and with no point to escape. Some unbooked pregnant mothers' 
delivery in the entrance and passages of the ward. Most reported that they even felt homesick. One participant was quoted as follow:

"I was so fearful of any emergency of unbooked mothers because of their complications followed by litigations... It was so difficult, what made me so fearful, was the fact that others made funny noise and sounds like animals, calling a nurse. Although I know they are just human beings like us but their behaviours differ completely from ours when they are in labour pains." PN3

According to Uys and Middleton [20], the fear is out of proportion to the actual danger posed within the sociocultural context. The fear can be out of losing control, not being able to cope and of physically being harmed. In this study, midwives were fearful because of the unusual behaviour by unbooked pregnant women such as making funny noises and literally screaming. In this instance, midwives also fear accountability and possible complications to the delivering women.

\section{- Shortage and incompetence of midwives}

Shortage and incompetency of midwives is a category under the main theme: experiences of midwives. Participants reported that there is a high rate of resignations and these resignations include skilled professionals like advanced midwives. Their shortage led to many specialised skills not performed. Some of the deaths are due to lack of advanced skills in performing certain procedures. One participant expressed her feeling as follow:

"I cannot deliver an obstructed or other complicated labour because I am not an advanced midwife... Sometimes unbooked cases come in numbers and with the current huge shortage of human resources and equipment and expected to ensure no deaths; this is a really frustrating situation". PN4

A study by Mosehle, Matlala, Thanyani \& Lumadi [17] found that many advanced midwives are able to perform skills in complicated labour cases as compared to nurses with basic midwifery course. They are scared to perform skills in abnormal labour cases because of their training exposure. Further, poor quality of care in the maternal health facilities is associated with shortage of midwives and their lacking skills to perform advanced procedures. Another study by Olonade, Olawande, Alabi \& Imhonopi [21] described in their study that shortage of basic equipment to perform necessary procedures became a serious concern as it is linked with maternal deaths in health facilities. Midwives were concerned about provision of quality care while having these unbearable challenges such as skills incompetence and their shortage.

\section{- Maternal incidences}

Maternal incidence is a subtheme under the categorical theme: shortage and incompetency of midwives. Maternal incidences may either be necessary or unnecessary depending to the nature of its occurrence [22]. In this study, necessary incidences refer to those incidences that occur whilst all the necessary activities 
to help the pregnant women were done but the women lost her infant baby or herself life. These types of incidences are investigated and the findings find all compliances in all parties involved in helping the women including their resources utilised accordingly in order to save the lives of both mother and infant.

On the other side, unnecessary incidences in this study are those incidences that occur because of the failure of the professionals to organise their activities for helping the women to deliver efficiently. On investigation, the findings revealed a failure on the side of the practitioners or hospital setting. These incidences emanate from human error or mistake despite available resources to help during management of unbooked pregnant women [16]. Unnecessary incidences might be due to a lack of communication, poor support from each other, and being unable to use the existing material resource to help the patient. Incidences where professionals fail to apply the existing guidelines and protocols resulting into a loss of lives are also regarded as unnecessary ones [22]. Broadly, poor health facility systems strengthening to manage their pregnancy women lead to unnecessary incidences. For instance, in primary health care, clinic staff continued failing to trace pregnant women in their catchment areas to attend the antenatal care services which lead to many unbooked cases leading to unnecessary incidences. In addition, rural hospitals fail to conduct outreach programmes in relation to maternal health and such failure cause some unnecessary incidences as it is their role to do so.

In this study, participants reported that shortage of midwives and their incompetency are the leading causes of maternal incidences. They further stated that these poor outcomes result in litigations under maternal health services. One participant expressed her feelings as follow:

"Eeh I remember one day I was alone in labour ward assisting a patient who was giving birth and another patient came whilst I was busy with the first one, and deliver his baby without my assistance and the woman had an MSB". PN5

Plenty of literatures revealed that many maternal incidences are being caused by huge shortage of midwives to manage maternity unit effectively [23]. South Africa is among countries reported poor health outcomes on maternal health. These poor health outcomes include MSBs, FSBs, perinatal and maternal deaths [2]. Despite these continuous numbers of incidences, midwives are expected to deliver quality of care irrespective of their working conditions [24].

\section{- Caring for unbooked pregnant mothers}

In details, care refers to those assistive, supportive, helping, facilitated, professional, moral and culturally accepted actions rendered to the individual, family or group, whilst feeling concern or interest, providing protection and showing attention to the one being cared for; through a competent and interactive therapeutic caring relationship [25].

Managing an unbooked pregnant case became a challenge in rural district hospitals because most of the midwives are not experienced and advanced in the 
maternity unit. Their biggest challenge is that they cannot manage working under pressure with inadequate resources and their incompetence to manage an emergency pregnant woman. Some studies around South Africa declared that rural district hospitals do not have a stationed doctor for maternity ward [23]. Doctors are allocated for the entire hospital, making it difficult for managing emergencies in the maternal health facilities. For example, some unbooked cases require urgent caesarean section to theatre and sometimes there are delays due to the inadequate medical doctors. Based on these well-founded facts, the researcher believed that having proper and functional primary health systems would help managing these types of patients before they come for labour delivery purposes.

Indeed, unbooked pregnant mothers presenting in labour is common phenomenon amongst the study population, and might contributing to a significantly to the high maternal mortality rate in developing countries. Multiple efforts to ensure utilisation of antenatal services were done and still in considerations. It also revealed that caring for these types of patients require both enough basic equipment and human resources. This would minimise some complications [26].

\section{- Inexperienced midwives}

However, incompetencies of midwives were a category from the main theme: caring for unbooked pregnant women. Participants reported that there were many experienced midwives who had resigned for various reasons between 2015 and 2017 respectively. The current nurse midwives are inexperienced staff in maternity unit. These participants expressed their feeling of uncomfortable in performing certain procedures because they do not have many work experiences and feel incompetency in some extent.

\section{- Lack of debriefing}

Despite the poor working conditions and other unbearable circumstances they encounter, the debriefing session is lacking which would provide some corrections and counselling where necessary. One participant was quoted as follow:

"You know Sir, this institution does not have any form of debriefing after any session of incidence, although some of us are aware of debriefing from our previous employers but staffs here cite that they are busy with other duties." PN6

Debriefing means a discussion that is held after an incident session which all aspect of events is deliberated and analysis is made. Debriefing after an actual critical event is an established good practice in maternal health to support affected midwives. The debriefing performance in maternity unit is supposed to be promoted by maternity team including management and other necessary stakeholders like Ambulance personnel. The aim is to facilitate discussion of actions and thought processes, encourage reflection, and ultimately assimilate improved behaviors into practice [27]. In this study, debriefing was a great quality and educational instrument that can potentially change team behavior and positively 
enhance maternal health outcomes.

\section{- Support system}

Support system is important for developing team building initiatives. Therefore, these groups cohesion strengthen coping skills. Nurses especially midwives need lots of support and time from supervisors. Effective communication between registered nurses and their managers could assist with developing coping mechanisms to support each other.

- Lack of support from managers

Lack of support from the managers was a category from the main theme support system. One participant expressed her problem as follow:

"As midwives we always face situations that can be very depressing, if a pregnant woman dies or if a baby dies.... The supervisors are not there for emotional support instead they want us to write an incidence report only." PN1

The abovementioned findings of participants are consistent with one of the studies by Jones-Berry [28] who found that midwives felt unsupported after they have experienced serious emergency that complicated into maternal death. The study also shown that there was not even a single manager caring and supporting them; they just wanted to get full report including incident report.

Support is a category of verbal communication is one of the God's great gifts bestowed to human [29]. Further, God not only created speaking potential with diverse dialects in the human body, but also taught him how to use it through inspiration, his inner instinct, or external guidance. Among different forms of communication in human communities, maternal health services require effective communication with the midwives if it is to be successful. Failure to support could potential complicate to demotivation of midwives on caring their daily duties.

\section{Conclusion and Recommendations}

In this study, the experiences of midwives were centered on their practical issues that would enhance quality of care in the maternal health facilities. The majority of experiences of midwives were supported by findings from other literature searches conducted. All the literature sources used in this study were based on the experiences of midwives for caring unbooked pregnant mothers. The participants expressed a need for management to participate during debriefing sessions. Their belief was that their support in these sessions would motivate their professional conduct in the maternal health facilities.

The study was aimed at exploring the experiences of midwives in a maternity unit as these experiences are central to the provision of quality of care in the maternal health facilities. The study findings have also shown that the experiences of midwives in a maternity unit are for provision of physical comfort, psychological support and adequate staffing and basic equipment. The findings 
of this study confirm previous findings and contribute additional evidence that poor health outcomes on maternal health facilities are associated with various factors such as staff incompetence, inadequate resources, labor complications, and the majority of midwives are newly qualified practitioners and poor working conditions.

Based on the abovementioned information provided, the researcher recommends that there should be collaboration between hospitals and serving primary health care clinics including community leaders. The effectiveness of this plan would assist in minimising self-referrals and unattended antenatal clients by clinics. The researcher also recommended that staff coverage should be considered including the employment of high skilled professionals. Lastly, the researcher recommends that some in-service trainings on the gaps identified would be conducted to minimise unnecessary adverse events.

One of the limitations of the study was that the study utilised small sample size of 10 participants. The information gathering was guided by data saturation in $6^{\text {th }}$ participant. The study was conducted only in public hospital in Libode and did not represent the majority of the country context.

\section{Acknowledgements}

The author expresses his warmth thanks to the midwives who participated in the study and the outside reviewers of this article until its approval for publication.

\section{Conflicts of Interest}

The author declares no conflicts of interest regarding the publication of this paper.

\section{References}

[1] Damian, D.J., Njau, B., Lisasi, E., Msuya, S.E. and Boulle, A. (2019) Trends in Maternal and Neonatal Mortality in South Africa: A Systematic Review. Systematic Reviews, 8, 76-85. https://doi.org/10.1186/s13643-019-0991-y

[2] Wabiri, N., Chersich, M. and Shisana, O. (2016) Growing Inequities in Maternal Health in South Africa: A Comparison of Serial National Household Surveys. BMC Pregnancy Childbirth 16, 256-265. https://doi.org/10.1186/s12884-016-1048-Z

[3] Agyepong, I.A., Kwamie, A., Frimpong, E., Defor, S., Ibrahim, A., Aryeetey, G.C., Lokossou, V. and Sombie, I. (2017) Spanning Maternal, Newborn and Child Health $(\mathrm{MNCH})$ and Health Systems Research Boundaries: Conducive and Limiting Health Systems Factors to Improving MNCH Outcomes in West Africa. Health Research Policy and Systems, 15, 54-70. https://doi.org/10.1186/s12961-017-0212-x

[4] Ten Hoope-Bender, T., De Bernis, L., Campbell, J., Downe, S., Fauveau, V. and Fogstad, H. (2014) Improvement of Maternal and New-born Health through Midwifery. The Lancet, 384, 1226-1235. https://doi.org/10.1016/S0140-6736(14)60930-2

[5] Jinga, N., Mongwenyana, C., Moolla. A., Malete, G. and Onoya, D. (2019) Reasons for Late Presentation for antenatal Care, Healthcare Providers' Perspective. BMC Health Service, 19, Article No. 1016. https://doi.org/10.1186/s12913-019-4855-X

[6] Okonofua, F.E., Ntoimo, L.F.C. and Ogu, R.N. (2017) Women's Perceptions of 
Reasons for Maternal Deaths: Implications for Policies and Programs for Preventing Maternal Deaths in Low-Income Countries. Health Care for Women International, 9, 95-109. https://doi.org/10.1080/07399332.2017.1365868

[7] Njoku, C.O., Emechebe, C.I., Eyong, E.M., Ukaga, J.T. and Anachuna, K.C. (2016) Prevalence and Risk Factors for Stillbirths in a Tertiary Hospital in Niger Delta Area of Nigeria: A Ten-Year Review. International Journal of Medicine and Biomedical Research, 5, 106-113. https://doi.org/10.14194/ijmbr.5.3.1

[8] Haddrill, R., Jones, G.L., Mitchell, C.A. and Anumba, D. (2014) Understanding Delayed Access to Antenatal Care: A Qualitative Study. BMC Pregnancy and Childbirth, 10, Article No. 207. https://doi.org/10.1186/1471-2393-14-207

[9] Osungbade, K.O. and Ayinde, O.O. (2014) Maternal Complication Prevention: Evidence from a Case-Control Study in Southwest Nigeria. African Journal of Primary Health Care \& Family Medicine, 6, a656. https://doi.org/10.4102/phcfm.v6i1.656

[10] Kaswa, R., Rupesinghe, G.F.D. and Longo-Mbenza, B. (2018) Exploring the Pregnant Women's Perspective of Late Booking of Antenatal Care Services at Mbekweni Health Centre in Eastern Cape, South Africa. African Journal of Primary Health Care \& Family Medicine, 10, e1-e9. https://doi.org/10.4102/phcfm.v10i1.1300

[11] Froneman, C., Van Wyk, N.C.V. and Mogale, R.S. (2019) Enhancing the Professional Dignity of Midwives: A Phenomenological Study. Nursing Ethics, 26, 1062-1074. https://doi.org/10.1177/0969733017739781

[12] WHO (2015) Progress on the Health-Related Millennium Development Goals (MDGs). WHO, Geneva.

[13] Emechebe, C.I., Njoku, C.O., Eyong, E.M., Maduekwe, K. and Ukaga, J.T. (2017) The Social Class and Reasons for Grand Multiparity in Calabar, Nigeria. Tropical Journal of Obstetrics and Gynecology, 33, 327-331. https://doi.org/10.4103/0189-5117.199808

[14] Sandy, P.T. (2013) Motives for Self-Harm: Views of Nurses in a Secure Unit. International Nursing Review, 60, 358-365. https://doi.org/10.1111/inr.12038

[15] Grove, S.K., Gray, J.R. and Burns, N. (2015) Understanding Nursing Research, Building Evidence-Based Practice. 6th Edition, Elsevier, Philadelphia.

[16] Department of Health (2017) Department of Health Annual Report 2017/2018. Department of Health, Pretoria.

[17] Mosehle, S., Matlala, T.G and Lumadi, T. (2019) Perceptions of Midwives on Shortage and Retention of Staff at a Public Hospital in Tshwane District. Curationis, 42, a1952. https://doi.org/10.4102/curationis.v42i1.1952

[18] Emotional Challenges (2017) Care-Research: Palliative Care Knowledge Network. https://www.caresearch.com.au/caresearch/tabid/431/Default.aspx\#2017

[19] Roets, M., Poggenpoel, M. and Myburgh, C. (2018) Psychiatric Nurses' Experience of Aggression amongst Colleagues. Health SA Gesondheid, 23, 1086-1091. https://doi.org/10.4102/hsag.v23i0.1086

[20] Uys, L. and Middleton, L. (2014) Mental Health Nursing a South African Perspective. 6th Edition, Juta, Cape Town.

[21] Olonade, O., Olawande, T.I., Alabi, O.J. and Imhonopi, D. (2019) Maternal Mortality and Maternal Health Care in Nigeria: Implications for Socio-Economic Development. Covenant University, Nigeria.

[22] Department of Health (2016) National Policy for Patient Safety Incident Reporting and Learning in the Public Health Sector of South Africa. Department of Health, Pretoria. 
[23] Musie, M.R., Peu M.D. and Bhana-Pema, V. (2019) Factors Hindering Midwives' Utilisation of Alternative Birth Positions during Labour in a Selected Public Hospital. African Journal of Primary Health Care \& Family Medicine, 11, a2071-a2079. https://doi.org/10.4102/phcfm.v11i1.2071

[24] Maphumulo, W.T. and Bhengu, B.R. (2019) Challenges of Quality Improvement in the Healthcare of South Africa Post-Apartheid: A Critical Review. Curationis, 42, a1901. https://doi.org/10.4102/curationis.v42i1.1901

[25] Sengane, M. (2013) “Mothers” Expectations of Midwives' Care during Labour in a Public Hospital in Gauteng. Curationis, 36, a320. https://doi.org/10.4102/curationis.v36i1.320

[26] Osungbade, K.O. and Ayinde, O.O. (2014) Maternal Complication Prevention; Evidence from a Case-Control Study in South West Africa. African Journal Primary Health Care Family Medicine, 6, 656-657. https://doi.org/10.4102/phcfm.v6i1.656

[27] Kessler, D.O., Cheng, A. and Mullan, P.C. (2015) Debriefing in the Emergency Department after Clinical Events: A Practical Guide. Annals of Emergency Medicine, 65, 690-698. https://doi.org/10.1016/j.annemergmed.2014.10.019

[28] Jones-Berry, S. (2019) The Crucial Gap in the People Plan's Workforce Target. Nursing Standard, 34, 51-53. https://doi.org/10.7748/ns.34.8.51.s14

[29] Bambaeeroo, F. and Shokrpour, N. (2017) The Impact of the Teachers' Non-Verbal Communication on Success in Teaching. Journal of Advances in Medical Education \& Professionalism, 5, 51-59. 